\title{
Correspondence
}

\section{A response to Allen Buchanan's views on decision making for terminally ill incompetents}

To the Editor:

Allen Buchanan's interesting Article in this edition of the American Journal of Law E Medicine ${ }^{1}$ adds another provocative opinion to the debate on the legal and ethical issues raised by the Saikewicz case. Although I welcome his thoughtful contribution, I regret to say that it contains some distortions of the arguments I advanced in this journal ${ }^{2}$ and elsewhere. ${ }^{3}$ If, as it appears, my arguments are to be taken as representative of the position of many other physicians, then they ought to be clearly understood and fairly presented. For this reason, I venture to extend the present debate with the following brief comments.

Like Charles Baron, ${ }^{4}$ Buchanan imputes to me a "paternalistic" position that I certainly do not hold and never stated. In their zeal to set up a target for arguments against "medical paternalism," neither Baron nor Buchanan is entirely accurate in interpreting what I said. I believe that, whenever possible, physicians should act only with the informed consent of their patients or, if the patient is legally incompetent, of the family or legal guardian. I said as much in three places in my Article in this journal ${ }^{5}$ and I made the same point earlier in an editorial in The New England Journal of Medicine. ${ }^{6}$ However, Baron and Buchanan chose to emphasize other statements that, when taken out of context, make me sound like an uncompromising "paternalist," appropriate for attack.

My position may have been misunderstood because I tried to explain that physicians often are forced to take responsibility for decisions that the patient (or, in the case of the incompetent patient, his family) is either

\footnotetext{
${ }^{1}$ Buchanan, Medical Paternalism or Legal Imperialism: Not the Only Alternatives in Saikewicztype Cases, 5 Aм. J. L. \& MEd. 97 (1979).

${ }^{2}$ Relman, The Saikewicz Decision: A Medical Viewpoint, 4 AM. J. L. \& MED. 233 (1978).

${ }^{3}$ Relman, The Saikewicz Decision: Judges as Physicians, 298 New England J. Med. 508 (1978).

${ }^{4}$ Baron, Medical Paternalism and the Rule of Law: A Reply to Dr. Relman, 4 AM. J. L. \& MeD. 337 (1979).

${ }^{5}$ Relman, supra note 2, at 236, 237, 242.

${ }^{6}$ Relman, supra note 3.
} 
unable or unwilling to make. The medical profession is, I believe, firmly agreed that physicians should never ignore the expressed wishes of patients or families and that they have an obligation to ascertain, if possible, what those wishes are. But the fact is that the debilitating effects of their disease or of the drugs they are receiving, or the anxiety and depression that often accompany the confrontation with death, often overwhelm terminally ill patients and make them incapable of discussing options with their physician. Furthermore, when such patients become legally incompetent their families may be so grief-stricken oi fearful that they are unable or unwilling to discuss the painful details of medical management. Thus families often expressly turn decision-making authority over to the physician, or else they may be so divided or uncertain in their views that they in effect abdicate responsibility, and the physician must take charge.

I did not say, as Buchanan implies, ${ }^{7}$ that the physician alone is able to understand what is in the best interests of the patient. What I believe, and what I said, is that the physician must be willing to make decisions when requested or when that otherwise is clearly necessary; and I explained that when patients are desperately or terminally ill, either or both of these conditions often apply. Buchanan expresses skepticism that families of terminally ill patients would ever have difficulty comprehending "the technical facts of the case" if the physician "makes a serious effort to communicate," ${ }^{8}$ but that is not the important question and it would be fruitless to pursue it further. The issue that divides us is not "family versus physician," but "family and physician" versus some outside agency.

The real question underlying this debate is: to what extent should society allow families, working together with physicians, to make life or death decisions for terminally ill incompetent family members? I see no need for the involvement of other elements of society in these private matters unless there are disputes, requests for help, or complaints of wrongdoing. Baron, Buchanan, and Annas, on the other hand, distrust families and physicians to varying degrees. Baron argues for routine judicialization of these decisions, a proposal aptly described by Buchanan as "legal imperialism." Buchanan proposes ethics committees that would establish procedural guidelines and provide routine post hoc surveillance of certain kinds of decisions. I am not sure exactly where Annas stands with respect to the views of Baron and Buchanan, but I know he disagrees with my position. ${ }^{9}$

An important element of the arguments advanced by all three of my colleagues in this debate is their distinction between "medical" and "moral"

\footnotetext{
${ }^{7}$ Buchanan, supra note 1 , at 10 .

${ }^{8} I d$.

9 Annas, Reconciling Quinlan and Saikewicz: Decision Making for the Terminally Ill Incompetent, 4 Ам. J. L. \& MED. 367 (1979).
} 
decisions. According to them, the "medical" decisions involve purely technical questions that are the sole and only proper domain of the physician. The "moral" decisions belong exclusively to the patient, and if he is legally incompetent they must be handled for him in some manner by society. Thus, Baron and Annas believe that "moral" decisions are legal matters and should be made in advance by the courts; Buchanan thinks "moral" decisions can be made, at least initially, by families with the advice of physicians, but he believes these decisions need routine post hoc review by ethics committees.

I reject the dichotomy between "medical" and "moral" decisions. In the first place, the distinction is often difficult if not impossible to make in actual clinical situations. ${ }^{10}$ The moral and technical aspects of medical practice are frequently inseparable, for the simple reason that people are not machines. Furthermore, as Cassell has argued so eloquently, ${ }^{11}$ few important clinical decisions can be made properly without consideration of the humanity of the patient; and this inevitably requires the weighing of moral issues. A purely technical physician could be a menace because his judgments would lack compassion and human understanding. I doubt that many patients would feel comfortable with such a person; they expect more than technical service when they consult their physician.

One of Buchanan's major disagreements with Baron's "legal imperialism" is on the grounds of impracticality; in my view Buchanan's own proposal is open to the same criticism. Aside from being unnecessary, routine review by ethics committees would be unattainable. The number of decisions that would have to be examined is enormous and the potential work load of a committee in a large hospital would be staggering. Given the difficulty of separating "medical" from "moral" decisions, ${ }^{12}$ I find it hard to envision how, in surveying hundreds of potential cases, an ethics committee would determine which should undergo full-scale examination. If the committee were to do a thorough and systematic job, the time, effort, and expense consumed by its surveys and deliberations would be enormous.

And what would be the purpose of it all? Buchanan makes his ethics committee sound like a quasi-judicial body seeking consistènt, rational, and principled decisions. But in the case of previously competent patients, surely the prime consideration is not rationality or consistency but simply what the patient himself would have wanted. Assuming good intentions, families and personal physicians are more qualified to make that judgment than a committee of strangers-or a judge. (As an aside, I must also observe that even if consistency were desirable in these circumstances, there is no

${ }^{10}$ Jackson \& Youngner, Patient Autonomy and "Death with Dignity": Some Clinical Caveats, 301 New England J. Med. 404 (1979).

11 Cassell, Making and Escaping Moral Decisions, 1 Hastings Center Studies 53 (1973).

${ }^{12}$ Jackson \& Youngner, supra note 10. 
reason to believe that each individual committee, with its own religious, cultural, social, and geographical characteristics, would always render judgments that are consistent with those of other committees.) In the instances of newborns or mental defectives, a better case could perhaps be made for Buchanan's ethics committee, because families and physicians would have no better insight into such patients' wishes than anyone else. But even here such committees seem inappropriate unless families and physicians are unable to agree.

To justify the effort and expense involved in Buchanan's proposal, one has to assume either that these committees are more qualified to determine the wishes of an incompetent patient than his well-intentioned family and physician or that families and physicians willfully neglect the interests of patients frequently enough to warrant some remedy not now available. I have already rejected the first assumption out of hand, although I concede that the issue is less clear when no one could possibly know the patient's wishes-for example, when the patient is a baby or is severely retarded. As for the second assumption, I would simply make two observations. First, conspiracy between the family and the physician against the patient must be very rare. Second, in those few instances in which conspiracy does occur, society already has available two post hoc remedies - the courts, and the review bodies of the medical profession that are backed by the licensing authority of the states. Admittedly, neither remedy may be as vigilant a watchdog as Buchanan might wish, because they need to be activated by complaints, but when one is dealing with rare abuses of a private and very sensitive matter, public involvement should be discriminating and limited.

Although I oppose routine involvement of ethics committees (or the courts) in the decisions of families and physicians, I do believe that ethics committees can be useful on a selective and advisory basis. There are clinical situations in which the advice of a committee might be very helpful to the family or the physician in dealing with a difficult case, but such advice is of greatest value when it is requested voluntarily and not mandated.

I have suggested that much of the concern about life-or-death decisions made by families and physicians would be allayed by full documentation in the medical record and by greater use of professional consultation. ${ }^{13}$ Whenever a decision is made to withhold or to terminate life-prolonging therapy of an incompetent patient, the medical record should show that the decision was made with the informed consent of the family and with the concurrence of several physicians who have no vested interest in the outcome. I regret that none of my colleagues in this debate discussed this idea. In my view, it is a far more practical way of protecting the interests of all

\footnotetext{
${ }^{13}$ Relman, supra note 2, at 242.
} 
concerned than is either of the alternatives suggested by Baron and Buchanan.

Many believe that "living wills" provide the best solution to this dilemma by giving people an opportunity to state their wishes about terminal care while they are still legally competent. However, as discussed elsewhere, I have serious reservations about such documents. ${ }^{14}$ If people feel the need to make some kind of advance arrangement, a much better plan would be the designation of a legal agent who could represent the interests of a patient after he becomes incompetent. ${ }^{15}$ Such an agent could then work with the physician, much as the patient himself would have done. This is a sensible idea and, if the law must become involved in these matters, I would favor this kind of "living will." Of course, this option requires some personal initiative and it is not open to minors or to adults who have never been legally competent.

No solution to this problem is perfect. We have to recognize that there is no ideal, foolproof way to guarantee that terminally ill incompetent patients will be treated exactly as they might have wished. We should therefore be looking for a moderate and practical approach that will work well in most cases and will not interfere with the essential task of caring for the incompetent patient in the most humane manner possible. Neither the Baron nor the Buchanan approach meets that need.

Arnold S. Relman, M.D., Editor

The New England Journal of Medicine

${ }^{14}$ Relman, Michigan's Sensible Living Will, 300 New England J. MEd. 1270 (1979).

${ }^{15} I d$. 